\title{
Clinical End Result in Indian Patients Undergoing Primary Percutaneous Coronary Intervention in Institution without Onsite Surgical Facilities
}

\author{
Agnel Saji ${ }^{1}$, Agra Shyni Raj², George Mathew Neeraakal ${ }^{3}$ \\ ${ }^{1,2}$ Department of Emergency Medicine, Rajah Charitable Medical Trust, Thrissur, Kerala, India. \\ ${ }^{3}$ Department of Cardiology, Rajah Charitable Medical Trust, Thrissur, Kerala, India.
}

\section{ABSTRACT}

\section{BACKGROUND}

Primary percutaneous coronary intervention is one of the treatment options for STelevation myocardial infarction and is relatively safer and superior to thrombolytic therapy. The decrease in time to reperfusion leads to decreased infarct size and hence incidence of major adverse cardiac events (MACE). This knowledge has led to the concept of off-site percutaneous coronary intervention centres (without surgical backup). However, performing primary percutaneous coronary intervention at centres without surgical backup has been controversial. Controversy arises regarding the safety and efficacy of primary percutaneous coronary intervention in centres without onsite surgical backup. No such studies have been available among Indian population regarding the outcome in patients undergoing primary coronary intervention in centres without surgical backup. Thus, our study focusses on one year clinical outcomes in Indian patients undergoing primary percutaneous coronary intervention without on-site surgical backup. ${ }^{1-8}$

\section{METHODS}

It was done as an observational, single centre, retrospective study. It included 139 patients, who were diagnosed with ST elevation myocardial infarction (STEMI) who underwent primary PCI from February 2019 to June 2020 at Rajah Hospital, Thrissur, Kerala, India. The primary endpoint of the study was occurrence of major adverse cardiac events, a sum of target vessel revascularisation (TLR), cardiac death, and myocardial infarction at one year after procedure.

\section{RESULTS}

$83.45 \%$ were males. $30.21 \%$ were hypertensives and $48.92 \%$ were diabetics. There were four cardiac deaths at 30-day follow-up and 4 (2.87 \%) events of TLR at one-year follow-up. And additionally, the mean age of population was 56.05 years.

\section{CONCLUSIONS}

Considering these results, it can be concluded that mainly in the developing countries like India; primary PCI can be performed safely at PCI centres which lack the facility of on-site surgical backup.

\section{KEY WORDS}

ST-Elevation Myocardial Infarction, Percutaneous Coronary Intervention, Coronary Artery Disease.
Corresponding Author:

Dr. Agnel Saji,

\#211/3, Nanjangud,

Karnataka, India.

E-mail: dr.agnelsaji@gmail.com

DOI: $10.14260 /$ jemds/2022/30

How to Cite This Article:

Saji A, Raj AS, Neeraakal GM. Clinical end result in Indian patients undergoing primary percutaneous coronary intervention in institution without onsite surgical facilities. J Evolution Med Dent Sci 2022;11(01):157-162,

$10.14260 / \mathrm{jemds} / 2022 / 30$

Submission 18-12-2021,

Peer Review 24-12-2021,

Acceptance 25-01-2022,

Published 29-01-2022.

Copyright (C) 2022 Agnel Saji et al. This is an open access article distributed under Creative Commons Attribution License [Attribution 4.0 International (CC BY 4.0)] 


\section{BACKGROUND}

Acute ST elevation myocardial infarction (AMI) has been one of the major causes of death throughout the world, especially in developing countries. At inception, the procedure of balloon angioplasty for treatment of CAD was time consuming as well as associated with augmented rate of complications. Therefore, it mandated the requirement of coronary artery bypass graft surgery (CABG) at the site of angioplasty in case if required. ${ }^{9}$ Although, with the advancement of time and the development of new technology and stents have led to reduction of time from ischaemia to reperfusion, and procedure time resulting in reduced infarct size and decreased incidence of major adverse cardiac events. Advancement in interventional cardiology techniques, equipment and pharmacology has contributed towards diminution of complications, leading to reduction in need for emergency $\mathrm{CABG}$ at Percutaneous Coronary Intervention (PCI) centres. ${ }^{10}$ Due to finesse in operators and facilities, the requirement of emergency $\mathrm{CABG}$ during $\mathrm{PCI}$ has been limited to only 0.3 to $0.6 \%$ of total cases. ${ }^{9,11}$

According to current international guidelines, during primary $\mathrm{PCI}$, in patients with significant multivessel disease, only the infarct-related artery (culprit lesion) should be treated, unless the patient is in cardiogenic shock or has persistent ischemia after PCI of the supposed culprit lesion (Steg et al. 2012). "However, more recently, three randomized trials showed reductions in ischemia-driven revascularization and variable effects on the risks of recurrent myocardial infarction and death with PCI of nonculprit stenosis" (Wald et al., 2013; Engstrom et al. 2015; Gershlick et al. 2015).

The use of stent over balloon angioplasty alone (Pinto et al. 2011; Steg et al. 2012) should be preferred because it reduces the incidence of restenosis and the rate of reintervention. For the same reason, stents coated with medication (drug-eluting stents) should be preferred to baremetal stents. However, since drug-eluting stents carry a high risk of intracoronary acute thrombosis, prolonged DAPT is mandatory in all patients receiving drug-eluting stents. Thus, drug-eluting stents should be preferred over bare-metal stents if the patient has no contraindications to prolonged DAPT (indication for oral anticoagulation or estimated high long-term bleeding risk) and is likely to be compliant.

If primary PCI is performed by an experienced radial operator, the radial access over the femoral access should be preferred, given the lower rate of accessible bleeding (Steg et al. 2012).

Emergency PCI can be divided into primary PCI, pharmaco-invasive therapy (pharmacological perfusion followed by PCI) and rescue PCI after failed pharmacological reperfusion. Urgent PCI in STEMI is strongly indicated (level 1 evidence) in patients with presentation to cardiological centres of excellence, contraindications to thrombolysis, high risk but with predicted small or moderate benefit from thrombolytic therapy (e.g., elderly, diabetic and with presentation beyond 3 hours), cardiogenic shock even up to 12-36 hours after infarction, failed thrombolysis and previous CABG.

A very few patients have contraindications to PCI. The major risk factor is from the use of anticoagulant therapy which could produce bleeding. Another complication is from the risk of contrast induced renal failure. Primary caution should be taken to prevent the occurrence of the same. PCI is limited by the risk of abrupt vessel closure and stenosis. But coronary stenting is superior to balloon angioplasty in preventing restenosis although survival and re-infarction benefits are less than in elective stent procedures. ${ }^{8}$

Door to balloon time contributes to a major role in the prognosis of ST-elevation MI patients. In ST elevation MI patients with symptoms of chest pain for a period $<12$ hour, if the patient can be transferred to a centre with PCI facility within 120 min- coronary reperfusion using stent is preferred over the pharmacological methods of reperfusion. Apart from this, the advised time from ST elevation MI diagnosis to crossing wire in PCI is $\leq 90 \mathrm{~min}$. Several measures and methods have been adopted to reduce this time delays, including field triage, training of healthcare providers in a STEMI-network, and retrospective clinical audits on time intervals, transmission of prehospital electrocardiography (ECG).

In the early days, PCI was only allowed to perform in the hospitals with on-site back-up for emergency cardiac surgery. However, due to the difficulty; during the last 10-15 years, the procedure has been expanded and started including in hospitals without on-site cardiac surgery (off-site PCI). With more and more off-site PCI centres ensure early revascularization in ST elevation MI patients living in remote areas where onsite PCI centres are not available.

On the darker side, 2004 American College of Cardiology/ American Heart Association practice guidelines for ST Segment Elevation Myocardial Infarction had recommended Class IIb for primary PCI in centres without cardiac surgery. ${ }^{12}$ The 2011 ACCF/AHA/SCAI guidelines have suggested that primary PCI can be performed in hospitals without on-site surgical back-up, only with apt planning for program development (Class IIa). However, without a proper plan for prompt shifting to a nearby cardiac surgery hospital or without suitable haemodynamic support capability during transfer, the guideline has recommended PCI as Class III. ${ }^{13}$ Even though literature on this matter is conflicting, PCI procedure done on institutions without surgical back up have increased exponentially, which resulted in the conduction and publication of several studies to juxtapose the safety and effectiveness of PCI at PCI centres without on-site surgical facilities and those with on-site CABG means. Fascinatingly these studies revealed no significant distinctness in results, when PCI was done between both centres at various followup periods.

However, none of such studies has reported in India with the same results to our best knowledge. Thus, this study intends to find the clinical outcomes of patients those who have undergone PCI in a centre without surgical backup. Please note, this is done as an observational study.

\section{METHODS}

This was done as an observational, single centre and retrospective study which included 139 patients who underwent primary PCI at our institution between February 2019 and June 2020. Baseline demographics include, 
angiographic data and cardiac history were compiled from patient's records and prospectively follow up data were assembled during patients follow up visits. The concerned consent was taken during the follow up or before they are being discharged. Patients admitted with acute STEMI were included in the study. But patients with significant comorbidities like severe impairment in liver or kidney, or anything that reduced the lifespan of the patient significantly, along with patients to whom dual antiplatelet therapy for one year cannot be given, with major or advanced cancers which limit the lifespan were excluded from study. Apart from this, those who couldn't give informed consent were not included in the study. The study has been approved by the Institutional Ethics Committee.

\section{End Point of Study}

The occurrence of MACE was considered the end points of study. MACE is a sum of cardiac death, target vessel revascularisation and myocardial infarction at one year after primary PCI. Apart from this, the incidence of stent thrombosis was also taken into consideration. Any death resulting from MI, fatal arrhythmia, unwitnessed death and death due to unknown reason were also included and all procedure-related deaths, low-output failure, encompassing those associated to concomitant treatment were categorised as cardiac death. ${ }^{14}$ "The MI was described as increase of cardiac troponin (cTn) levels $\{>5 \times 99$ th percentile of Upper Reference Limit $\}$ in patients with normal baseline levels ( $\leq$ 99th percentile URL) or rise of cTn levels $>20 \%$ when baseline values are high and stable or decreasing. 15 "Pathological Q-waves are defined with reference to amplitude, location and depth in minimum two contiguous leads. A ISR was referred to restenosis within stent or within $5 \mathrm{~mm}$ distal or proximal stent edges. ${ }^{14}$

PCI procedure: The standard procedure of the PCI includes a percutaneous approach via radial or femoral artery. Clopidogrel (bolus dose of $600 \mathrm{mg}$ and then $75 \mathrm{mg}$ daily) or ticagrelor (bolus dose of $180 \mathrm{mg}$ and then $90 \mathrm{mg}$ daily) and aspirin (325 mg loading dose and then $150 \mathrm{mg}$ once daily) were administered to every patient. Apart from this unfractionated heparin ( $60 \mathrm{U} / \mathrm{kg}$ body weight) was also given as IV bolus. The decision to make between plain old balloon angioplasty (POBA) or drug eluting stent (DES) compared to bare metal stent (BMS) or glycoprotein IIb/IIIa inhibitors and the use of an intra-aortic balloon pump was left to the discretion of the doctor who conducts the procedure. In patients those who had high thrombus load was performed on thrombectomy for better results.

Follow-up data were collected for the outcomes in the patients, looking for the major cardiac adverse events at 30 days, 6 months and one year. For this reason, follow up data were collected during the regular revisits and revisits in the emergency room, and telephonically, who haven't showed up in the follow up visit.

\section{Statistical Analysis}

For quantitative variable means and SD (standard deviations) were calculated. Whereas categorical variables were recorded in terms of percentages and counts. Using KaplanMeier method cumulative incidents are calculated. All analyses which containing statics were done with the help of Statistical Package for Social Sciences Software.

\section{RESULTS}

Out of 139 patients, males were 116 (83.45\%) and 56.05 years was the mean age of all the patients. And diabetic patients were sixty-eight (48.92\%) and forty-two (30.21\%) were hypertensives. The mean systolic and diastolic blood pressure were $139.3 \pm 31$ and $83.2 \pm 18.2$. The mean random blood sugar was 196 with a standard deviation of 98.78 . The average ejection fraction was $44.17 \pm 6.68 \%$. Three $(2.15 \%)$ patients were presented with cardiogenic shock in the emergency room. Nine patients presented with cardiac arrhythmia in which one patient $(0.71 \%)$ had atrial fibrillation and eight (5.75\%) had ventricular fibrillation or ventricular tachycardia. Twenty-two patients had history of smoking while seventeen patients were known to have dyslipidaemia. There was incidence of pericarditis in one patient following myocardial infraction. Four patients had pulmonary oedema in the initial presentation to hospital. Estimated glomerular filtration rate was less than 60 $\mathrm{mL} / \mathrm{min} / 1.73 \mathrm{~m} 2$ in eight (5.75 \%) patients.

\begin{tabular}{|c|c|}
\hline Baseline Demographics & Values \\
\hline Age of the patients (mean \pm SD, years) & $56.05 \pm 10.73$ \\
\hline Male, n (\%) & $116(83.45 \%)$ \\
\hline Systolic BP (mean \pm SD, mmHg) & $139.3 \pm 31$ \\
\hline Diastolic BP (mean $\pm \mathrm{SD}, \mathrm{mmHg})$ & $83.2 \pm 18.2$ \\
\hline RBS (mean $\pm \mathrm{SD}, \mathrm{mmol} / \mathrm{L})$ & $196 \pm 98.78$ \\
\hline Type 2 diabetes mellitus, $\mathrm{n}(\%)$ & $68(48.92 \%)$ \\
\hline $\mathrm{AF}, \mathrm{n} \%$ & $1(0.71 \%)$ \\
\hline Hyper-cholesterolaemia, n (\%) & $17(12.23 \%)$ \\
\hline Smoking, $\mathrm{n}(\%)$ & $22(15.82 \%)$ \\
\hline Cardiogenic shock, n (\%) & $3(2.15 \%)$ \\
\hline Ejection fraction (mean \pm SD) & $44.17 \pm 6.68$ \\
\hline VT or VF, n (\%) & $8(5.75 \%)$ \\
\hline Hypertension, $\mathrm{n}(\%)$ & $42(30.21 \%)$ \\
\hline Complete heart block, n (\%) & $9(6.47 \%)$ \\
\hline Reinfarction, n (\%) & $3(2.15 \%)$ \\
\hline Pericarditis, n (\%) & $1(0.71 \%)$ \\
\hline Renal insufficiency at screening, n (\%) & $7(5.03 \%)$ \\
\hline LVF pulmonary oedema, n (\%) & $4(2.87 \%)$ \\
\hline Bleeding, $\mathrm{n}(\%)$ & $4(2.87 \%)$ \\
\hline CVA, n (\%) & $1(0.71 \%)$ \\
\hline $\mathrm{eGFR}<60 \mathrm{~mL} / \mathrm{min} / 1.73 \mathrm{~m} 2, \mathrm{n}(\%)$ & $8(5.75 \%)$ \\
\hline \multicolumn{2}{|c|}{\begin{tabular}{|c|} 
Table 1. \\
\end{tabular}} \\
\hline \multicolumn{2}{|c|}{$\begin{array}{l}\text { BMI- Body Mass Index, BP- Blood Pressure, VF-Ventricular Fibrillation, GFR- } \\
\text { Glomerular Filtration Rate, VT- Ventricular Tachycardia, LVF- Left Ventricular } \\
\text { Failure, RBS-Random Blood Sugar, CVA-Cerebro Vascular Accident, AF- Atrial } \\
\text { Fibrillation }\end{array}$} \\
\hline
\end{tabular}

The characteristics of the study population has been detailed in Table no. 1. In 139 patients there was a total of 143 lesions, of which 54 (37.76\%) lesions were located in the in right coronary artery, 73 (51.04\%) lesions were located in left anterior descending artery, $1(0.69 \%)$ in left main artery and $15(10.48 \%)$ in left circumflex artery. Sadly, thirty-nine $(28.05 \%)$ patients presented with triple vessel disease (given in Table no. 2). For percutaneous coronary intervention, right radial route was the preferred route for the procedure performing doctor, which came to a number of $113(81.29 \%)$. Drug eluting stents (DES) were implanted in 131(94.24 \%) lesions. For 26 lesions (13.3\%) direct stenting was performed but POBA was only performed in 8(5.75\%) lesions. The flow achieved in 130(93.52\%) was TIMI 3 lesions (details given in Table 3). Cardiac deaths occurred within 30 days of procedure was sadly four (2.87 \%). MACE rate at the end of one year was $8(5.75 \%)$, which included 
$4(2.87 \%)$ TLR and $4(2.87 \%)$ cardiac deaths. The total occurrence of stent thrombosis at one year follow-up (details given in Table 4) were three (2.15\%).

\begin{tabular}{|cc|}
\hline $\begin{array}{c}\text { Character } \\
\text { MI }\end{array}$ & Patient (N= 139)/ Lesions (N= 143) \\
ST elevation MI, $\mathrm{n}(\%)$ & $139(100 \%)$ \\
Target vessel & $15(10.48 \%)$ \\
LCX, $\mathrm{n}(\%)$ & $54(37.76 \%)$ \\
RCA, n (\%) & $73(51.04 \%)$ \\
LAD, $\mathrm{n}(\%)$ & $1(0.69 \%)$ \\
LM, $\mathrm{n}(\%)$ & Table 2. Lesional Characteristics \\
\hline \multicolumn{2}{|c|}{} \\
\hline LM- Left Main, STEMI- ST-Elevation Myocardial Infarction, RCA- Right Coronary \\
Artery, LCX- Left Circumflex Artery, LAD- Left Anterior Descending Artery
\end{tabular}

\begin{tabular}{|cc|}
\hline Characteristics & Patient (N=139) \\
Right femoral approach, n (\%) & $11381.29 \%)$ \\
Right radial approach, n (\%) & $26(18.70 \%)$ \\
POBA, n (\%) & $8(5.75 \%)$ \\
DES, n (\%) & $131(94.24 \%)$ \\
TIMI 0, n (\%) & $0(0 \%)$ \\
TIMI 1, n (\%) & $3(2.15 \%)$ \\
TIMI 2, n (\%) & $6(4.31 \%)$ \\
TIMI 3, n (\%) & $130(93.52 \%)$ \\
\hline Table 3. Procedural Characteristics of the Patients \\
\hline DES- Drug Eluting Stents, POBA- Plain Old Balloon Angioplasty, TIMI- Thrombolysis \\
in Myocardial Infarction. \\
\hline
\end{tabular}

\begin{tabular}{|c|c|c|c|}
\hline Clinical Outcomes & $\begin{array}{l}\text { Follow-up } \\
\text { at } 30 \text { Days }\end{array}$ & $\begin{array}{l}\text { Follow-up } \\
\text { at } 6 \text { Months }\end{array}$ & $\begin{array}{l}\text { Follow-up } \\
\text { at } 1 \text { Year }\end{array}$ \\
\hline Death from any cause, $\mathrm{n}(\%)$ & $5(3.59 \%)$ & $5(3.59 \%)$ & $6(4.31 \%)$ \\
\hline Cardiac death, $\mathrm{n}(\%)$ & $4(2.87 \%)$ & $4(2.87 \%)$ & $4(2.87 \%)$ \\
\hline $\begin{array}{l}\text { Death from non-cardiac } \\
\text { issues, } \mathrm{n}(\%)\end{array}$ & $0(0 \%)$ & $1(0.71 \%)$ & $1(0.71 \%)$ \\
\hline MI, n (\%) & $0(0 \%)$ & $0(0 \%)$ & $0(0 \%)$ \\
\hline $\begin{array}{l}\text { Revascularisation of target } \\
\text { lesion, } \mathrm{n}(\%)\end{array}$ & $1(0.71 \%)$ & $3(2.15 \%)$ & $4(2.87 \%)$ \\
\hline $\begin{array}{l}\text { Revascularisation of target } \\
\text { vessel, } n(\%)\end{array}$ & $2(1.43 \%)$ & $4(2.87 \%)$ & $8(5.75 \%)$ \\
\hline Thrombosis of stent, n (\%) & $1(0.71 \%)$ & $1(0.71 \%)$ & $3(2.15 \%)$ \\
\hline $\begin{array}{c}\text { Major-adverse cardiac event, } \\
\mathrm{n}(\%)\end{array}$ & $5(3.59 \%)$ & $7(5.03 \%)$ & $8(5.75 \%)$ \\
\hline
\end{tabular}

\section{DISCUSSION}

Percutaneous coronary intervention has been considered as a major advancement in the medical field. Emergence of percutaneous coronary intervention have reduced the complications due to balloon angioplasty, and led to reduced requirement of surgical backup. Early mortality, i.e., mortality within the hospital and 30-day mortality, was the major concern related to percutaneous coronary intervention in centres without surgical backup. A clinically successful percutaneous coronary intervention includes anatomical success as well as procedural success where patients should be free of symptoms of myocardial ischemia after they recover from the intervention. While a long-lasting procedural success means that the patient must have symptom free period for more than six months after the procedure. The major advantage of percutaneous coronary intervention is its smoothness of approach and avoiding requirement of anaesthesia, thoracotomy. Brain related complications are rare, and prolonged convalescence are other advantages. If needed, repeat percutaneous coronary intervention can be performed easily than a re-operative surgery, and achievement of revascularisation is quicker in emergency situations.

Clear visualisation of the target vessel stenosis and its corresponding vascular branches are the major dependent factors behind the success of percutaneous coronary intervention. The operator should keep in mind regarding the arteries beyond the blockage as this is equally important because of the chance for collateral flow and myocardial support if the vessel were to occlude abruptly. Increasing age, unstable angina, comorbidities, pre-existing heart disease or renal failure, past history of myocardial infarction, diabetes mellitus, a large area of myocardium at risk, multivessel disease and degree of collateral circulation in coronary arteries can affect the outcomes of PCI adversely.

\section{PCI Procedure Involves the Following Steps}

Insertion of catheter into radial or femoral artery, administration of heparin, then engagement of coronary ostium using guide wire followed by pre dilatation of lesion and positioning of the stent.

Most of the percutaneous coronary intervention procedure are successful but also some of them won't give good result. For example, the lumen may be too narrow for the catheter or guide wire to pass through a thrombus and may end up tearing the inner lining of the artery at balloon site. Treatment may not be successful even if chemical agents are used to prevent clot formation. For a fraction of percutaneous coronary intervention procedure, emergent CABG surgery might be required. Those who undergo percutaneous coronary intervention are less sensitive to heart attack.

Some adverse effects are reported now a days, even when the PCI mortality is low. At the catheter entry site, some patients may develop an aneurysm while some others develop a hematoma.

Early restenosis and the inability to relieve many occluded vessels with atherosclerotic disease are some other disadvantages in PCI. Restenosis adversely affect long-term clinical success compared to short-term success. The longterm result has improved to less than $10 \%$ of patients for the recurrent narrowing or blockage when the PCI technique advanced from balloon, to balloon plus stent, and to balloon plus drug-eluting stent. From the studies it is reported as there is no evidence of narrowing or blockage even after 12 months and the majority remain open in stented area for many years. Incidentally the remaining areas may require an additional stent in future. Some of patients may end up having either stent thrombus or additional arterial areas may develop narrowing or blockage, because of their unhealthy diet and medication adherence. They are more likely to have cholesterol accumulation in their coronary arteries and may lead to arterial narrowing.

In this country, it is widely accepted according to health authority and PCI without on-site cardiac surgery back up is performed for a bunch of people. Even if the data is insufficient, PCI can be delivered safely in this way when we apply best standard to such operation programmes. Almost every health care says 'standard of care' is a particular treatment rather than settling down for a treatment used. Standard care means how a qualified practitioner as well as an interventional cardiologist can manage patients. Numerous studies have been conducted and compared the early mortality rate of PCI centres with and without onsite surgical backup. Recently, Koolen et al. had compared MACE rates between the percutaneous coronary intervention centre 
without surgical backup and percutaneous coronary intervention centre with on-site surgical backup procedures at 30 days and 6 months follow-up. Cardiac deaths within 30 days for the percutaneous coronary intervention group without onsite surgical backup and percutaneous coronary intervention group with surgical backup were $2.3 \%$ and 1.8 $\%$, respectively $(\mathrm{p}=1.000)$. While, the cardiac deaths at six months were $2.4 \%$ and $1.8 \%$, respectively. ${ }^{16}$ However, there are studies which have reported range of in-hospital deaths without surgical backup to be widespread between $4 \%$ and 9.8\%. ${ }^{9,17}$ A study in United Kingdom had reported the favour of percutaneous coronary intervention centre without onsite surgical cover in terms of 30-day mortality, HR: 0.87; $95 \% \mathrm{CI}$ : $0.71-1.06 ; p=0.16$, and at 1 year mortality, HR: $0.92 ; 95 \%$ CI: 0.71 - 1.06; $\mathrm{p}=0.26$, in patients with any indication, but lacked statistical significance. ${ }^{18}$ Similarly, a report from National Cardiovascular Data Registry had stated observance of similar procedural success, morbidity, emergency cardiac surgery rates and mortality in percutaneous coronary intervention centres without on-site surgical backup and in cases that required emergency surgery. ${ }^{19}$ In a meta-analysis, Simard $\mathrm{T}$ et al. had observed that primary percutaneous coronary intervention as well as elective percutaneous coronary intervention could be performed safely at percutaneous coronary intervention centres without on-site surgical backup, without an increase in mortality rates or other complications. ${ }^{10}$ In recent study, the mortality rate at 30 days was $3.1 \%$ while early death rate of primary PCI was $5 \%{ }^{20-22}$ While the real-world registries (irrespective of procedures with surgical backup or procedures without surgical backup) exhibit higher mortality rates ranging from $7 \%$ to $10.5 \% .{ }^{23-25}$ Thus, it can be conferred that the availability of surgical backup does not greatly affect the early mortality rates. Furthermore, the literature states that coronary reperfusion should be achieved at the earliest as mortality is closely related to the time delay between symptom onset and reperfusion. ${ }^{26}$ Thus, mortality has been a major dependent of time delay rather than availability of surgical backup. In view of this, a door-to-balloon time of $\leq 90$ mins is recommended to achieve optimal results. ${ }^{27}$ In third world like India, it's a task for agrarians to reach out hospitals at emergency situations. And this PCI centres at community level hospitals might bring a great outcome even without onsite surgical backup. Such establishment benefits more patients and can avoid delay in reperfusion time. In order to achieve full benefit of the facility, the skill of the operator as well as selection criteria of the patient is equally important.

Lacks of comparative arm and retrospective data are the limitation of this study. And the information on survey was also derived from a single hospital.

\section{CONCLUSIONS}

According to this study we can conclude that, it is safe to perform primary PCI at centres without any surgical backup with enough facilities, but skilled surgeon must be available and also patient should be apt for procedure. The procedure should be performed by skilled operator and patient with correct indications where the outcome should be satisfactory which is beneficial to patient with high quality manner, regardless where procedure is performed. This must be the principal standard for all PCI procedures even If the PCI have to be done without on-site cardiac surgical backup because otherwise the service will be unavailable. But the procedure should be done by an equally qualified interventional cardiologist who should do in this setting, so when PCI procedure must be done without an on-site cardiac backup can be contemplate standard of care.

Data sharing statement provided by the authors is available with the full text of this article at jemds.com.

Financial or other competing interests: None.

Disclosure forms provided by the authors are available with the full text of this article at jemds.com.

\section{REFERENCES}

[1] Shahian DM, Meyer GS, Yeh RW, et al. Percutaneous coronary interventions without on-site cardiac surgical backup. N Engl J Med 2012;366:1814-23.

[2] Tebbe U, Hochadel M, Bramlage $P$, et al. In-hospital outcomes after elective and non-elective percutaneous coronary interventions in hospitals with and without onsite cardiac surgery backup. Clin Res Cardiol 2009;98(11):701-7.

[3] Hannan EL, Zhong Y, Racz M, et al. Outcomes for patients with ST-Elevation myocardial infarction in hospitals with and without onsite coronary artery bypass graft surgery: The New York State Experience. Circ Cardiovasc Interv 2009;2:519-27.

[4] Ting HH, Raveendran G, Lennon RJ, et al. A total of 1,007 percutaneous coronary interventions without onsite cardiac surgery: acute and long-term outcomes. J Am Coll Cardiol 2006;47(8):1713-21.

[5] Tomassini F, Gagnor A, Montali N, et al. Primary percutaneous coronary intervention without on-site cardiac surgery backup in unselected patients with STsegment-elevation myocardial infarction: the Rivoli ST-segment elevation myocardial infarction (RISTEMI) registry. Cardiovasc Revasc Med 2013;14(1):9-13.

[6] Singh M, Holmes DR, Dehmer GJ, et al. Percutaneous coronary intervention at centres with and without onsite surgery: a meta-analysis. JAMA 2011;306(22):2487-94.

[7] Mol KA, Rahel B, Eerens F, et al. The first year of the Venlo percutaneous coronary intervention program: procedural and 6-month clinical outcomes. Neth Heart J 2013;21(10):449-55.

[8] Peels J0, Hautvast RW, de Swart JB, et al. Percutaneous coronary intervention without on site surgical backup: two-years registry of a large Dutch community hospital. Int J Cardiol 2009;132(1):59-65.

[9] Yang EH, Gumina RJ, Lennon RJ, et al. Emergency coronary artery bypass surgery for percutaneous coronary interventions: changes in the incidence, clinical characteristics, and indications from 1979 to 2003. J Am Coll Cardiol 2005;46(11):2004-9.

[10] Simard T, Hibbert B, Pourdjabbar A, et al. Percutaneous coronary intervention with or without on-site coronary artery bypass surgery: a systematic review and metaanalysis. Int J Cardiol 2013;167(1):197-204.

[11] Seshadri N, Whitlow PL, Acharya N, et al. Emergency coronary artery bypass surgery in the contemporary 
percutaneous coronary intervention era. Circulation 2002;106(18):2346-50.

[12] Antman EM, Anbe DT, Armstrong PW, et al. ACC/AHA guidelines for the management of patients with STelevation myocardial infarction-executive summary: a report of the American College of Cardiology/American Heart Association Task Force on Practice Guidelines (Writing Committee to Revise the 1999 Guidelines for the Management of Patients With Acute Myocardial Infarction). Circulation 2004;110(5):588-636.

[13] Levine GN, Bates ER, Blankenship JC, et al. 2011 ACCF/AHA/SCAI guideline for percutaneous coronary intervention a report of the American College of Cardiology Foundation/American Heart Association Task Force on Practice Guidelines and the Society for Cardiovascular Angiography and Interventions. Circulation 2011;124(23):e574-651.

[14] Cutlip DE, Windecker S, Mehran R, et al. Clinical end points in coronary stent trials: a case for standardized definitions. Circulation 2007;115(17):2344-51.

[15] Thygesen K, Alpert JS, Jaffe AS, et al. Third universal definition of myocardial infarction. Eur Heart J 2012;33(20):2551-67.

[16] Koolen KH, Mol KA, Rahel BM, et al. Off-site primary percutaneous coronary intervention in a new centre is safe: comparing clinical outcomes with a hospital with surgical backup. Neth Heart J 2016;24(10):581-8.

[17] Pride YB, Canto JG, Frederick PD, et al. Outcomes among patients with ST-segment-elevation myocardial infarction presenting to interventional hospitals with and without on-site cardiac surgery. Circ Cardiovasc Qual Outcomes 2009;2(6):574-82.

[18] Garg S, Anderson SG, Oldroyd K, et al. Outcomes of percutaneous coronary intervention performed at offsite versus onsite surgical centres in the United Kingdom. J Am Coll Cardiol 2015;66(4):363-72.

[19] Kutcher MA, Klein LW, Ou FS, et al. Percutaneous coronary interventions in facilities without cardiac surgery on site: a report from the National Cardiovascular Data Registry (NCDR). J Am Coll Cardiol 2009;54(1):16-24.
[20] Stone GW, Witzenbichler B, Guagliumi G, et al. Bivalirudin during primary PCI in acute myocardial infarction. N Engl J Med 2008;358(21):2218-30.

[21] Stone GW, Grines CL, Cox DA, et al. Comparison of angioplasty with stenting, with or without abciximab, in acute myocardial infarction. $\mathrm{N}$ Engl J Med 2002;346(13):957-66.

[22] Valgimigli M, Campo G, Percoco G, et al. Comparison of angioplasty with infusion of tirofiban or abciximab and with implantation of sirolimus-eluting or uncoated stents for acute myocardial infarction: the MULTISTRATEGY randomized trial. JAMA 2008;299(15):1788-99.

[23] Carlsson J, James SN, Ståhle E, et al. Outcome of percutaneous coronary intervention in hospitals with and without on-site cardiac surgery standby. Heart 2007;93(3):335-8.

[24] Di Chiara A, Chiarella F, Savonitto S, et al. Epidemiology of acute myocardial infarction in the Italian CCU network: the BLITZ study. Eur Heart J 2003;24(18):1616-29.

[25] Shiraishi J, Kohno Y, Sawada T, et al. In-hospital outcomes of primary percutaneous coronary interventions performed at hospitals with and without on-site coronary artery bypass graft surgery. Circ J 2007;71(8):1208-12.

[26] De Luca G, Suryapranata H, Ottervanger JP, et al. Time delay to treatment and mortality in primary angioplasty for acute myocardial infarction: every minute of delay counts. Circulation 2004;109(10):1223-5.

[27] Kushner FG, Hand M, Smith SC, et al. 2009 Focused Updates: ACC/AHA guidelines for the management of patients with ST-Elevation myocardial infarction (Updating the 2004 Guideline and 2007 Focused Update) and ACC/AHA/SCAI guidelines on percutaneous coronary intervention (Updating the 2005 Guideline and 2007 Focused Update). A Report of the American College of Cardiology Foundation/American Heart Association Task Force on Practice Guidelines. Circulation 2009;120(22):2271-306. 